특발망막전막에서 유리체절제술 후 유두황반신경섬유다발두께 변화에 대한 고찰

\title{
Evaluation of Papillomacular Nerve Fiber Bundle Thickness Change after Vitrectomy Surgery for Idiopathic Epiretinal Membrane
}

\author{
장규환 ${ }^{1}$, 안자영 ${ }^{1}$, 손준홍 ${ }^{1}$, 황덕진 $^{1,2}$ \\ Kyu Hwan Jang ${ }^{1}$, Ja Young Ahn ${ }^{1}$, Joon Hong Sohn ${ }^{1}$, Daniel Duck-Jin Hwang ${ }^{1,2}$ \\ 1한길안과병원, ${ }^{2}$ 가톨릭관동대학교 의과대학 안과학교실 \\ ${ }^{1}$ Hangil Eye Hospital, Incheon, Korea \\ ${ }^{2}$ Department of Ophthalmology, Catholic Kwandong University College of Medicine, Incheon, Korea
}

Purpose: To observe changes in the papillomacular nerve fiber bundle (PMB) after pars plana vitrectomy (PPV) in patients with idiopathic epiretinal membrane (iERM) and to compare the surgical outcomes of PPV with and without air tamponade.

Methods: From 2015 to 2017, medical records were retrospectively analyzed for patients who had received at least one year of follow-up after vitrectomy with iERM.

Results: A total of 89 patients with 89 eyes were included in the study. In both groups (group with and without air tamponade) the mean best-corrected visual acuity (BCVA) after surgery improved significantly from 3 months to 1 year after surgery compared with preoperatively. The thickness of the PMB tended to increase gradually a month post-surgery; however, it showed a decline 3-months and 1-year post-operatively. The PMB thickness significantly increased until 6 months after surgery compared with the thickness of the opposite eye, but gradually decreased, and there was no significant difference at 1 year after surgery. There was no significant correlation between the thickness of the PMB and BCVA at 1 year postoperative. No difference between BCVA and PMB thickness was noted between the two groups at any point before or after the surgery.

Conclusions: After vitrectomy in patients with iERM, PMB thickness increased temporarily and subsequently decreased, showing a significant difference at 3-months and 1-year post-surgery. However, PMB thickness did not show a significant difference compared with that of the opposite eye. BCVA improved significantly compared to its preoperative status, but there was no significant correlation between PMB thickness and BCVA 1-year postoperatively. Air tamponade did not significantly affect changes in visual acuity and PMB thickness during the 1 year postoperatively.

Keywords: Air tamponade; Best corrected visual acuity; Idiopathic epiretinal membrane; Papillomacular nerve fiber bundle; Vitrectomy

\footnotetext{
Address reprint requests to Daniel Duck-Jin Hwang, MD

Hangil Eye Hospital, \#35 Bupyeong-daero, Bupyeong-gu, Incheon 21388, Korea

Tel: 82-32-503-3322, Fax: 82-32-504-3322

E-mail: danieldjhwang@gmail.com
}

Received: 2020. 3. 31.

Revised: 2020. 5. 10.

Accepted: 2020. 5. 27. 


\section{서론}

유리체절제술은 현재 안과에서 가장 많이 시행되고 있는 대표 적인 수술 중 한 가지로, 기존 보고들에 따르면 유리체절제술을 시행하였을 때, 후유리체박리를 일으키거나 내경계막벗김술 등 에 따른 기계적인 손상 및 눈속조명기에 의한 광독성, 인도사이

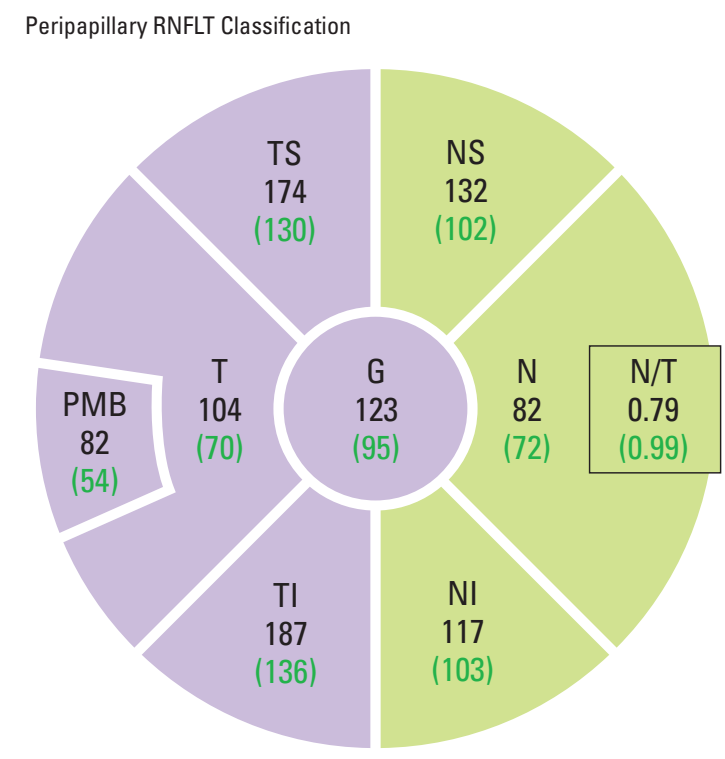

\section{Above normal limits}

Figure 1. Papillomacular nerve fiber bundle (PMB) measurement method using optical coherence tomography (OCT) Spectralis Nsite Axonal Analytics Software. The thickness of PMB is displayed using OCT Spectralis Nsite Axonal Analytics Software (right eye). G = global; RNFLT = retinal nerve fiber layer thickness; TS = superotemporal; NS = superonasal; $\mathrm{T}=$ temporal; $\mathrm{N}=$ nasal; $\mathrm{N} / \mathrm{T}=$ nasal/temporal; $\mathrm{Tl}=$ inferotemporal; $\mathrm{Nl}=$ inferonasal.
아닌그린의 망막 독성 등에 의해 망막신경섬유층 결손이 발생 하거나 망막신경섬유층의 두께가 얇아질 수 있다고 하였다[1-5]. 유두황반신경섬유다발(papillomacular nerve fiber bundle)은 진행된 녹내장에서도 가장 마지막까지 손상되지 않고 남아있는 시신경다발 중 하나로[6], 이전 보고들에 따르면 비동맥전방허 혈성시신경증 혹은 개방각녹내장 환자들에게서 이러한 유두황 반신경섬유다발의 두께는 중심 시력 및 시야에 중요한 역할을 한다고 알려져 있다[7,8].

하지만 기존 보고들 중 유리체절제술 후 유두주위망막신경섬 유층의 두께 변화를 살펴본 논문들은 있었지만, 유두황반신경 섬유다발의 두께 변화를 지켜본 논문은 없었다. 이에 우리는 망 막전막을 주소로 유리체절제술을 받은 환자들에게서 수술 후 유두황반신경섬유다발의 두께가 어떠한 변화를 보이는지 경과 관찰을 하여 분석하기로 하였으며, 충전물에 의한 차이를 보이 는지도 함께 확인하기 위해 수술 후 안내 충전물을 공기로 시행 한 군과 충전을 시행하지 않은 군으로 나누어 함께 분석하였다.

\section{대상과 방법}

본 연구는 한길안과병원에서 2015년부터 2017년까지 망막전막 으로 유리체절제술을 시행한 환자들 중 최소 1 년간 경과 관 찰을 한 환자들을 대상으로 의무기록을 후향적으로 분석하 였다. 본 연구에서 망막전막은 스펙트럼영역 빛간섭단층촬영 검사(Spectralis ${ }^{\circledR}$ Optical Coherence Tomography; Heidelberg Engineering, Heidelberg, Germany)를 통하여 확진하였으며, 같 은 검사 기계의 내장된 프로그램인 동심원 스캔 방식을 이용하 여 유두황반신경섬유다발의 두께를 측정하였다(papillomacular bundle, 338-8 $8^{\circ}$ Spectralis Nsite Axonal Analytics Software, Heidelberg Engineering) (Fig. 1). 황반부를 침범하는 질환인 당 뇨망막병증에 의한 황반부종이나 황반변성이 있는 경우, 시신

Table 1. Baseline characteristics of all patients with iERM

\begin{tabular}{lcccc}
\hline Parameter & Total $(\mathrm{n}=89)$ & BSS $(\mathrm{n}=41)$ & Air $(\mathrm{n}=48)$ & $p$-value \\
\hline Age (years) & $65.33 \pm 7.93$ & $65.15 \pm 8.06$ & $65.48 \pm 7.91$ & $0.845^{*}$ \\
Sex (M/F) & $25 / 64$ & $12 / 29$ & $13 / 35$ & $0.819^{\dagger}$ \\
Operated eye (right/left) & $49 / 40$ & $24 / 17$ & $25 / 23$ & $0.542^{\dagger}$ \\
VA (logMAR) & $0.34 \pm 0.25$ & $0.30 \pm 0.24$ & $0.37 \pm 0.27$ & $0.158^{*}$ \\
IOP & $15.22 \pm 2.62$ & $15.32 \pm 2.69$ & $15.13 \pm 2.58$ & $0.737^{*}$ \\
Macular thickness $(\mu \mathrm{m})$ & $408.55 \pm 70.20$ & $402.16 \pm 61.12$ & $415.24 \pm 78.82$ & $0.897^{*}$ \\
\hline
\end{tabular}

Values are presented as mean \pm standard deviation or number.

iERM = idiopathic epiretinal membrane; BSS = balanced salt solution; $M / F=$ male/female; $V A=$ visual acuity; logMAR = logarithm of minimum angle of resolution; IOP = intraocular pressure.

${ }^{*} p$-value derived by independent $t$ test; ${ }^{\dagger} p$-value derived by Pearson's chi-square test. 
Table 2. Changes in visual acuity of the BSS and Air groups over 1 year

\begin{tabular}{lcccc}
\hline Parameter & Total & BSS & Air & $p$-value \\
\hline Pre-op & $0.34 \pm 0.25$ & $0.30 \pm 0.24$ & $0.37 \pm 0.27$ & 0.158 \\
1 month & $0.31 \pm 0.23$ & $0.29 \pm 0.22$ & $0.32 \pm 0.23$ & 0.625 \\
& $(0.397)$ & $(0.979)$ & $(0.261)$ & \\
3 month & $0.23 \pm 0.18$ & $0.21 \pm 0.2$ & $0.26 \pm 0.17$ & 0.275 \\
& $(<0.001)$ & $(0.123)$ & $(0.001)$ & \\
6 month & $0.20 \pm 0.17$ & $0.19 \pm 0.19$ & $0.20 \pm 0.16$ & 0.761 \\
& $(<0.001)$ & $(0.010)$ & $(<0.001)$ & \\
1 year & $0.19 \pm 0.15$ & $0.17 \pm 0.14$ & $0.20 \pm 0.15$ & 0.316 \\
& $(<0.001)$ & $(0.004)$ & $(<0.001)$ & \\
\hline
\end{tabular}

The value in parentheses is the $p$-value compared with before operation (paired $t$ test).

$\mathrm{BSS}=$ balanced salt solution.

${ }^{*} p$-value derived by independent $t$ test.
경두께에 영향을 줄 수 있는 질환들인 녹내장이나 녹내장 의증 으로 진단 받은 경우 등은 연구에서 제외하였다.

모든 유리체절제술은 한 명의 숙련된 술자(D.D.H)에 의해 시행 되었으며, 25게이지 경결막무봉합 유리체절제술(transconjunctival sutureless vitrectomy)을 시행하였다. 테논낭하 리도카인 마취 와 모니터 감시 마취하 중심부와 주변부 유리체절제술을 시 행하였으며, 25게이지 플러스 유리체 절제 시스템을 이용하였 다(Constellation Vision System, Alcon Laboratories, Inc., Fort Worth, TX, USA). 이후 망막전막 제거와 함께 내경계막을 벗긴 뒤, 모든 환자에게서 주변부 $360^{\circ}$ 에 안내레이저광응고술을 시 행하였다. 수술장 내 빛간섭단층촬영기기(intraoperative OCT, RESCAN 700, Zeiss Meditec AG, Jena, Germany)를 통해 망막 전막이 제거되었음을 확인하였고, 망막 주변부 열공이나 격자 형 망막변성 등이 확인되었을 때는 유리체강 내를 공기로 충전 (Air군)하였으며, 이외의 경우(BSS군)는 평형염액으로 채운 뒤 수술을 마쳤다.
A
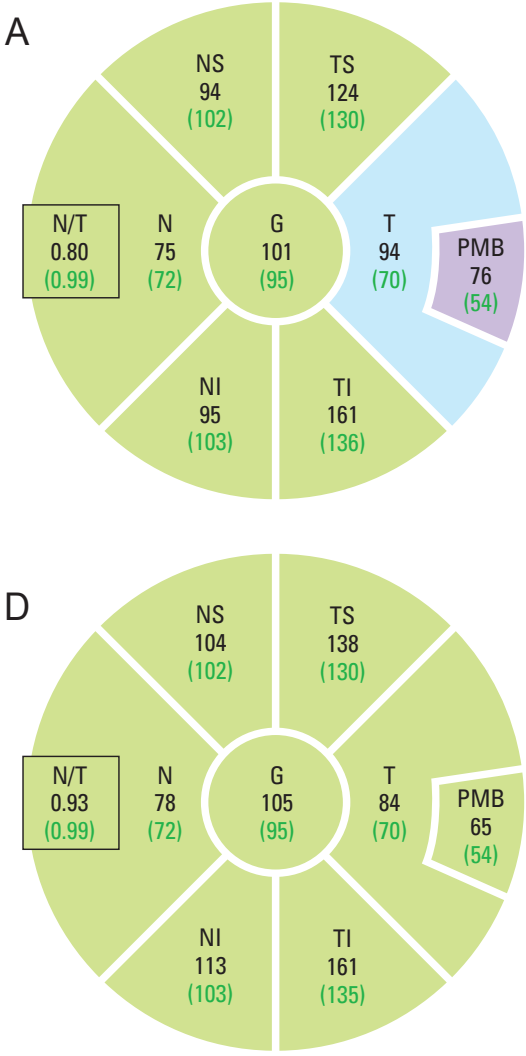

B
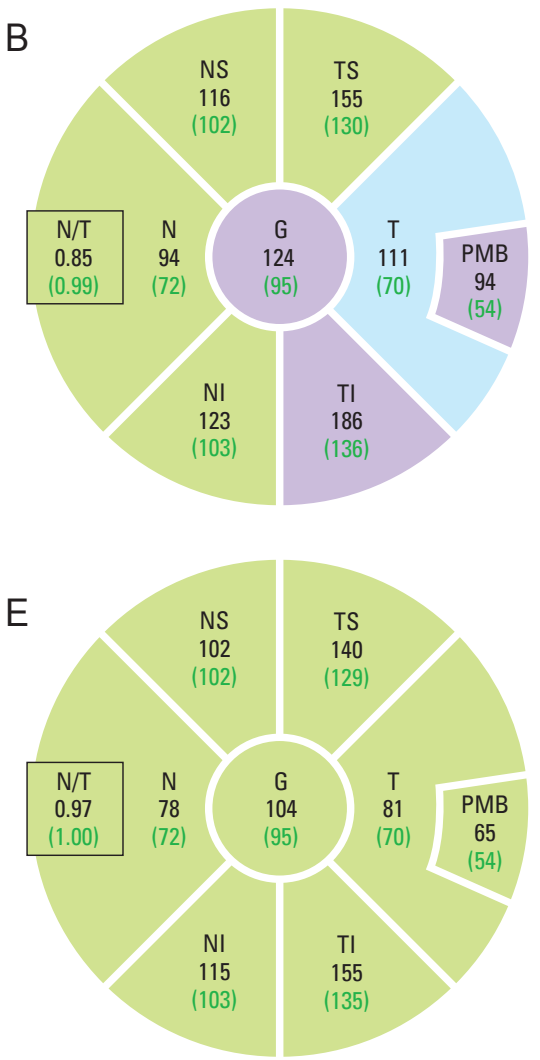
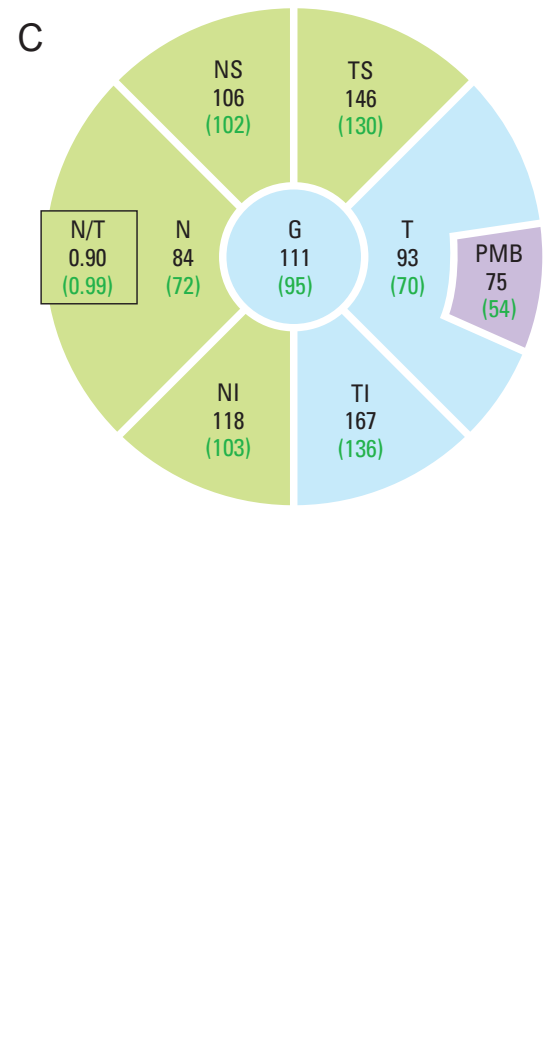

Figure 2. Papillomacular nerve fiber bundle (PMB) changes in optical coherence tomography (OCT) Spectralis Nsite Axonal Analytics Software after surgery. (A) Preoperative PMB value. (B) One month after surgery. PMB value increased to 94. (C) Three months after surgery. The PMB value was reduced to 75. (D) Six months after surgery. The PMB value was further reduced to 65. (E) One year after surgery. The PMB value is 65. G= global; RNFLT = retinal nerve fiber layer thickness; TS = superotemporal; NS = superonasal; $\mathrm{T}=$ temporal; $\mathrm{N}=$ nasal; $\mathrm{N} / \mathrm{T}=\mathrm{nasal} / \mathrm{temporal} ; \mathrm{Tl}=\mathrm{in}-$ ferotemporal; $\mathrm{NI}=$ inferonasal. 
환자들에게 수술 전, 수술 후 1개월, 3개월, 6개월, 1년 방문 시마다 세극등현미경검사, 안저검사, 최대교정시력 측정, 안압 측정, 굴절검사, 빛간섭단층촬영을 시행하였다. 본 연구는 헬싱 키선언에 준하여 시행되었으며, 한길안과병원 임상시험심사위원 회로부터 승인을 받았다(IRB no. 20008).

\section{결과}

본 연구에는 총 89 명 89 안이 포함되었다. 이들의 평균 연령은 $65.33 \pm 7.93$ 세였으며, 성별은 남자 25명, 여자 64명이었다. 수 술 전 평균 최대교정시력( $\log \mathrm{MAR})$ 은 $0.34 \pm 0.25$ 로 두 군 간에 차이를 보이지 않았으며, 안압도 $15.22 \pm 2.62$ 로 두 군 간에 차 이를 보이지 않았다. 술 전 황반부두께 또한 $408.55 \pm 70.20 \mu \mathrm{m}$ 로 두 군 간에 차이를 보이지 않았다(Table 1).

수술 후 평균 시력은 술 전과 비교하였을 때 1 개월째부터 점 차 호전되는 모습을 보이며, 3 개월 이후부터는 유의한 시력의 호전 정도를 보였다. 최종적으로 1년째의 최대교정시력은 0.19 \pm 0.15 로 술 전과 비교하였을 때 통계적으로 유의하게 호전된 모습을 보였다 $(p<0.001)$. 술 전과 술 후 모든 시점에서 두 군 간의 차이를 보이지는 않았다(Table 2).

유두황반신경섬유다발의 두께는 수술 후 1 개월에는 다소 증 가하는 경향을 보이다가, 3 개월 이후부터는 유의하게 감소하는 소견을 보였다 $(p<0.001)$. 술 후 1년째에는 평균 두께 $69.19 \pm$ $13.28 \mu \mathrm{m}$ 로 술 전과 비교 시 통계적으로 유의한 차이를 보였다 $(p<0.001)$ (Fig. 2). 시력과 마찬가지로 술 전과 술 후 모든 시 점에서 두 군 간의 차이를 보이지는 않았다(Table 3, Fig. 3). 수 술 반대안의 술 전 유두황반신경섬유다발두께와 비교했을 시,

Table 3. Changes in papillomacular bundle thickness of the BSS and Air groups over 1 year

\begin{tabular}{lcccc}
\hline Period & Total & BSS & Air & $p$-value $^{*}$ \\
\hline Pre-op & $84.38 \pm 19.93$ & $85.19 \pm 23.58$ & $83.66 \pm 16.21$ & 0.676 \\
1 month & $88.23 \pm 16.04$ & $89.03 \pm 17.44$ & $87.49 \pm 14.81$ & 0.673 \\
& $(0.112)$ & $(0.546)$ & $(0.067)$ & \\
3 month & $75.00 \pm 14.62$ & $76.26 \pm 12.12$ & $73.7 \pm 16.91$ & 0.477 \\
& $(<0.001)$ & $(0.015)$ & $(0.005)$ & \\
6 month & $72.14 \pm 13.77$ & $73.19 \pm 12.00$ & $71.09 \pm 15.46$ & 0.547 \\
& $(<0.001)$ & $(0.002)$ & $(0.002)$ & \\
1 year & $69.19 \pm 13.28$ & $68.54 \pm 12.65$ & $69.83 \pm 14.03$ & 0.688 \\
& $(<0.001)$ & $(0.001)$ & $(<0.001)$ & \\
\hline
\end{tabular}

The value in parentheses is the $p$-value compared with before operation (paired $t$ test).

BSS $=$ balanced salt solution .

${ }^{*} p$-value derived by independent $t$ test.
두 군 모두 술 전부터 술 후 6개월까지는 유의하게 두께가 증가 되어 있었다. 하지만 술 후 1 개월부터 BSS군과 Air군 모두 두께 가 점차 감소하여 최종적으로 1 년째 경과 관찰 시(BSS군 68.54 $\pm 12.65 \mu \mathrm{m}$, Air군의 $69.83 \pm 14.03 \mu \mathrm{m})$ 에는 반대안의 두께 (BSS군 $64.81 \pm 10.66 \mu \mathrm{m}$, Air군의 $64.13 \pm 13.46 \mu \mathrm{m}$ )와 유의 한 차이를 보이지 않았다 $(p=0.118, p=0.118)$. 술 후 1년째 유 두황반신경섬유다발의 두께와 최대교정시력 간에는 유의한 상 관관계를 보이지 않았다 $(p=0.788$, Pearson correlation).

고찰

본 연구에서는 특발망막전막 환자들의 유리체절제술 후 시력 과 유두황반신경섬유다발의 변화를 살펴보았으며, 수술 중 안 내 충전물을 공기로 시행한 군과 평형염액으로 시행한 군으로 나누어서 분석하였다.

본 논문의 결과에 따르면, 시력의 경우 술 전과 비교 시 두 군 모두 술 후 1개월부터 호전되는 양상을 보이며, 술 후 3개월부터 술 후 1 년까지는 두 군 모두에서 유의한 시력호전을 보였다. 경 과 관찰 기간 동안 두 군 간에 유의한 시력차이를 보이지는 않 았으며, 이러한 결과를 보았을 때 수술 중 안내 충전물을 기체 나 평형염액으로 선택하는 것이 시력에는 큰 영향을 주지는 않 는 것으로 보인다. 이는 Leitritz et al. [9]의 이전 연구에서도 밝

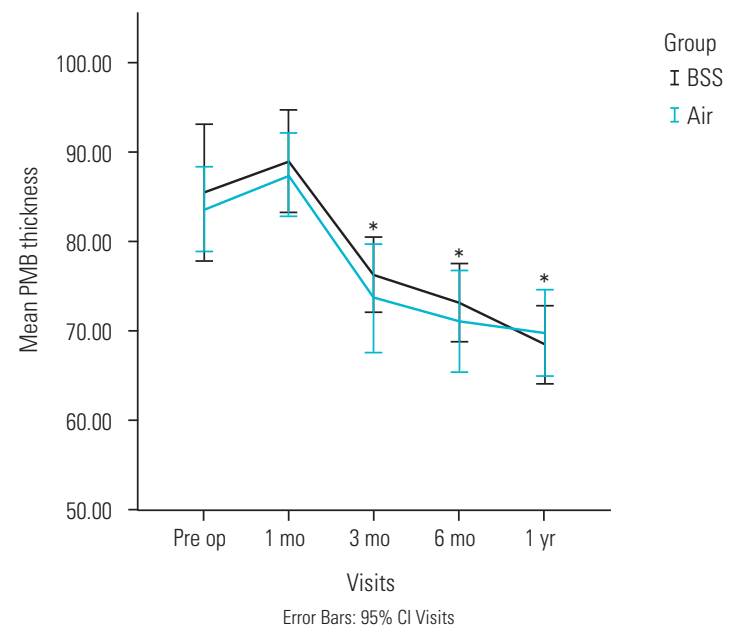

Figure 3. Temporal changes in papillomacular bundle thickness by group. In both groups (group with and group without air tamponade), papillomacular nerve fiber bundle (PMB) thickness was significantly decreased at 3, 6, and 12 months postoperatively. However, the PMB thickness at 1 year postoperative was not significantly different from the PMB thickness of the opposite eye. $p$-values less than 0.05 are marked with ${ }^{*}$. BSS $=$ balanced salt solution; $\mathrm{Cl}=$ confidence interval. 
혀진 바 있으며, 그들은 비교적 짧은 기간인 3개월간 80안을 기 체군과 평형염액군으로 나누어 시력을 비교한 결과 두 군 간에 유의한 시력차이가 없음을 발표한 바 있다.

이전 Takahashi et al. [8]과 Kobayashi et al. [10]의 발표에 따 르면 개방각녹내장 환자에서 유두황반신경섬유다발의 두께는 중심시력 및 시야와 매우 밀접한 상관관계가 있다고 하였다. 유 두황반신경섬유다발의 두께가 얇을수록 시력은 낮았고 두꺼울 수록 시력은 높았다. 본 논문에서는 술 후 1년째 최대교정시력 과 유두황반신경섬유다발의 두께 간의 상관관계도 밝히고자 하 였지만 유의한 상관관계를 보이지는 않았다. 하지만 이는 술 전 망막전막의 정도 및 술 후 호전 상태 등이 환자 개인마다 차이 가 있었던 부분을 고려해야 할 것으로 보이며, 또한 본 논문에 서는 1년째 유두황반신경섬유다발의 두께값과 반대안의 술 전 값과의 비교 시 차이가 없었는데, 이를 고려하였을 때 유두황 반신경섬유다발이 술 전과 비교하여 유의한 손상이 없었으므 로 시력에 큰 영향을 주지 않았을 가능성도 배제할 수 없을 것 으로 생각된다.

본 연구의 결과상 유두황반신경섬유다발의 두께는 술 후 일 시적으로 1 개월째까지 증가하였다가 이후 3 개월째부터 1 년째까 지 점차적으로 감소하는 추세를 보인다. 술 후 1년째에는 술 전 과 비교 시 유의한 차이를 나타내었지만, 이를 반대안의 초기 두께와 비교했을 시에는 유의한 차이를 나타내지 않았다. 이러 한 변화는 공기 충전군과 비충전군에서 모두 같게 나타났다. 술 후 1 개월째 발생하는 일시적인 두께 증가는 유리체절제술 자체 에 의한 염증 반응으로부터 기원하거나, 후유리체박리 진행 도 중 시신경유두에 가해질 수 있는 직접적인 손상, 혹은 인도사이 아닌그린 염색 등에 의한 일시적인 염증 등이 원인일 수 있겠다 $[2,4,5]$. 이후 이러한 효과가 감소하고, 망막전막의 견인력이 제거 되어 점차 두께가 감소하는 것이라 생각된다[11]. 또한 직접적인 비교는 아니지만, 위치상 유두황반신경섬유다발과 밀접한 관계 가 있는 시신경유두주위 이측 망막신경섬유층의 두께의 변화를 유리체절제술 후 관찰한 보고에 따르면, 이측 망막신경섬유층의 두께값의 경우는 술 전과 비교하였을 때도 유의하게 감소하였 지만, 술 후 12 개월째 반대안과 비교하였을 때도 유의하게 낮아 졌다 하였다[11]. 하지만 본 논문에서 관찰한 유두황반신경섬유 다발의 경우는 술 후 1 년까지 경과 관찰을 하여도 반대안의 값 보다 더 감소하지는 않은 것으로 보인다. 아주 심하게 진행된 녹 내장 환자들에게서도 유두황반신경섬유다발은 마지막까지 보 존되는 신경섬유 중 하나로[6], 이로 유추해 보았을 때, 유두황 반신경섬유다발의 변화를 1년간의 경과 관찰로는 충분히 파악 할 수 없거나, 술 후에도 다른 부위에 비해 영향을 덜 받을 가 능성을 생각해 볼 수 있을 것이다. Kokame [12]은 유리체절제술 후 나타나는 시야 이상의 원인 중 하나로 유리체절제술 시 삽입 하는 주입삽입관의 위치가 이측 아래에 위치할 경우, 망막의 비 측 위쪽에 영향을 미치어 결론적으로 시야 장애는 이측 아래에
나타난다고 하였다. 비교적 중심부에 위치하는 유두황반신경섬 유다발의 경우는 이러한 주입삽입관의 영향을 다른 이측 망막 신경섬유층보다 덜 받을 수 있을 것이며, 이러한 차이도 유두 황반신경섬유다발두께 변화에 영향을 주었을 것으로 생각된다.

비교적 적은 수의 환자를 대상으로 후향적 연구를 수행한 것 이 본 연구의 대표적인 제한점이며, 시야검사를 함께 진행하지 못하여 시야의 변화를 측정하지 못했던 것도 한계라 할 수 있 을 것이다. 또한 반대안과 술 후 매 시점에서의 비교를 시행하 지 못한 것도 제한점이라 할 수 있겠다. 하지만 이러한 제한점들 에도 불구하고 본 논문은 유리체절제술 후 유두황반신경섬유 다발의 변화를 밝힌 첫 번째 논문이라는 점에서 큰 의의를 가 질 수 있을 것이다.

결론적으로 특발망막전막에서 유리체절제술 후 유두황반신 경섬유다발은 공기 충전 유무와 관계없이 일시적으로 술 후 1개 월 때 증가하였다가 술 후 1년째는 술 전과 유의한 차이를 보이 도록 감소하지만, 반대안과 비교 시 유의한 차이를 나타내지 않 았다. 또한 두 군 모두에서 시력은 술 전과 비교 시 유의하게 호 전되었으며, 술 후 1년째 유두황반신경섬유다발의 두께와 최대 교정시력 간에는 유의한 상관관계를 보이지 않았다. 이로 미루 어 보았을 때 유두황반신경섬유다발은 유리체절제술 후 일어나 는 변화에 있어서 다른 이측 신경섬유다발보다 변동성이 적다 는 가능성을 제기할 수 있을 것이며, 또한 공기 충전술은 술 후 유두황반신경섬유다발과 중심시력 변화에 있어서 유의한 변화 를 주지 않으므로, 반드시 필요한 술기라 할 수는 없을 것이다.

\section{Conflicts of Interest}

The authors declare no conflicts of interest relevant to this article.

\section{References}

1. Mariotti $C$, Nicolai $M$, Longo $A$, et al. Peripapillary retinal nerve fiber thickness changes after vitrectomy for epiretinal membrane in eyes with and without vitreous detachment. Retina 2017;37:2304-9.

2. Yonemura N, Hirata A, Hasumura T, Negi A. Fundus changes corresponding to visual field defects after vitrectomy for macular hole. Ophthalmology 2001;108:1638-43.

3. Yan $H$, Dhurjon L, Chow DR, et al. Visual field defect after pars plana vitrectomy. Ophthalmology 1998;105:1612-6.

4. Uemura A, Kanda S, Sakamoto Y, Kita H. Visual field defects after uneventful vitrectomy for epiretinal membrane with indocyanine green-assisted internal limiting membrane peeling. Am J 
Ophthalmol 2003;136:252-7.

5. Russell SR, Hageman GS. Optic disc, foveal, and extrafoveal damage due to surgical separation of the vitreous. Arch Ophthalmol 2001;119:1653-8.

6. Chihara E, Tanihara H. Parameters associated with papillomacular bundle defects in glaucoma. Graefes Arch Clin Exp Ophthalmol 1992;230:511-7.

7. Rebolleda G, Sánchez-Sánchez C, González-López JJ, et al. Papillomacular bundle and inner retinal thicknesses correlate with visual acuity in nonarteritic anterior ischemic optic neuropathy. Invest Ophthalmol Vis Sci 2015;56:682-92.

8. Takahashi N, Omodaka K, Pak K, et al. Evaluation of papillomacular nerve fiber bundle thickness in glaucoma patients with visual acuity disturbance. Curr Eye Res 2020;45:847-53.

9. Leitritz MA, Ziemssen F, Voykov B, et al. Early postoperative changes of the foveal surface in epiretinal membranes: comparison of 23-gauge macular surgery with air vs. balanced salt solution. Graefes Arch Clin Exp Ophthalmol 2014;252:1213-9.

10. Kobayashi W, Kunikata H, Omodaka K, et al. Correlation of papillomacular nerve fiber bundle thickness with central visual function in open-angle glaucoma. J Ophthalmol 2015;2015:460918.

11. Lee SB, Shin YI, Jo YJ, Kim JY. Longitudinal changes in retinal nerve fiber layer thickness after vitrectomy for epiretinal membrane. Invest Ophthalmol Vis Sci 2014;55:6607-11.

12. Kokame GT. Visual field defects after vitrectomy with fluid-air exchange. Am J Ophthalmol 2000;130:653-4.

\section{국문초록}

\section{특발망막전막에서 유리체절제술 후 유두황반신경섬유다발두께 변화에 대한 고찰}

목적: 특발망막전막으로 유리체절제술을 받은 환자들에서 술 후 유두황반신경섬유다발(papillomacular nerve fiber bundle, $\mathrm{PMB})$ 의 변화를 관찰하고, 충전물에 의한 차이를 보이는지 확인하기 위해 안내 충전물을 공기로 시행한 군과 충전을 시행하지 않은 군 으로 나누어 분석하였다.

대상과 방법: 2015년부터 2017년까지 특발망막전막으로 유리체절제술을 시행한 환자들 중 최소 1년간 경과 관찰을 한 환자들을 대상 으로 의무기록을 후향적으로 분석하였다.

결과: 총 89명 89안이 포함되었으며, 두 군 전체에서 술 후 평균 시력은 술 전과 비교 시 3개월 이후부터 1년째까지 유의하게 호전되었 고, $\mathrm{PMB}$ 의 두께는 술 후 1개월까지 증가하다가 3개월 이후부터 1년까지 유의하게 감소하는 소견을 보였으며, 반대안의 PMB 두께와 비교 시 술 후 6 개월까지는 유의하게 두께가 증가되어 있었지만 술 후 1년째에는 유의한 차이를 보이지 않았다. 또한, 두 군 모두 술 후 1년째 $\mathrm{PMB}$ 의 두께와 최대교정시력 간에는 유의한 상관관계를 보이지 않았다. 두 군을 비교하였을 때, 시력과 $\mathrm{PMB}$ 의 두께는 모든 시 점에서 차이를 보이지 않았다.

결론: 특발망막전막으로 유리체절제술을 시행한 후 $\mathrm{PMB}$ 는 술 후 3개월부터 1년째까지 유의하게 감소하였지만, 반대안과 비교 시 유의 한 차이를 보이지는 않았다. 시력은 술 전과 비교 시 유의하게 호전되었으나, 술 후 1년째 $\mathrm{PMB}$ 의 두께와는 유의한 상관관계를 보이지 않았다. 공기 충전은 술 후 1년 동안 시력 및 PMB 두께의 변화에 유의한 영향을 주지 않았다. 